2006-01-01

\title{
Easy Grocery: 3D visualization in e-grocery
}

Somerville, J

http://hdl.handle.net/10026.1/8548

10.1109/iv.2006.47

Tenth International Conference on Information Visualisation (IV'06)

IEEE

All content in PEARL is protected by copyright law. Author manuscripts are made available in accordance with publisher policies. Please cite only the published version using the details provided on the item record or document. In the absence of an open licence (e.g. Creative Commons), permissions for further reuse of content should be sought from the publisher or author. 


\title{
Easy Grocery: 3D Visualization in e-Grocery
}

\author{
J. Somerville, L. J. Stuart, N. Barlow \\ The Visualization Lab, Centre for Interactive Intelligent Systems, \\ University of Plymouth, Plymouth, UK. \\ \{jared.somerville@plymouth.ac.uk, liz.stuart@plymouth.ac.uk,nigel.barlow@plymouth.ac.uk\}
}

\begin{abstract}
There are many deficiencies in the traditional electronic commerce schema. The main problem for consideration is the text and picture based design that underpins current HTML systems.

This paper presents the online grocery shopping system called Easy Grocery which is available at www.easygrocery.co.uk. This system is based on the innovative concept of using a $3 D$ system as an interface to the user during their shopping experience. Furthermore, this $3 D$ system follows the mental model of the user as opposed to that of the developer. Additionally, the user is able to select the layout of the online store so that it matches the layout of their local store, thus enabling even new users to exploit their own knowledge of how items are organised to shop efficiently. The Easy Grocery system demonstrates that $3 D$ online shopping can provide significant advantages for both consumers and retailers.
\end{abstract}

\section{Grocery Shopping}

The whole concept and experience of Grocery shopping has undergone a complete transformation over the last century. Historically, the industrial revolution saw the advent of a new wave of technologies which significantly affected key issues such as Transportation and the use of factories [1]. A new channel for the distribution of groceries evolved in which multiple shops, or "chains" were established. The ensuing price vs quality challenges persuaded smaller local suppliers to group together as organized chains. National brands were recognized, pricing systems were developed and market leaders naturally evolved.

Modern developments include the self-service system, centralized distribution, Co-Operatives, foreign food imports and the arrival of the supermarket. In 1997, Seth et al. [1] estimated that $2 \%$ of an average adult life was spent inside a supermarket. Thus, supermarkets have become an important part of our society today.

\section{Shopping online}

In 1990, Berners-Lee [2] released the first World Wide Web (Web) browser. During the "dot com" boom of the 1990s, many grocery chains joined the Web by offering online grocery ordering. Despite high predictions at that time, the online grocery market (e-grocery) has not realized the heights that were forecast [3]. However, the e-grocery market has undergone a smaller amount of consistent growth. One of the reasons for the reduced (albeit stable) growth was defined by Kempiak et al. [4]. They found that the "high-touch" characteristic of many grocery items results in the necessity for consumers to physically and/or visually inspect the quality of the specific items they are purchasing.

Clearly consumers who have specific time limitations constitute a significant portion of the e-grocery market. However, there are other significant groups in society for which e-grocery is very important, namely, consumers with mobility problems and disabilities. Clearly, the busy queue based traditional shopping environments are not ideally suited to Disabled or Elderly consumers. Experiments [5] have shown that the "current (supermarket based), inarguably efficient retail system does not take the needs of the elderly and disabled into account". Therefore, it is not surprising that Cude et al. [6] found that almost 15\% of egrocery shoppers cite physical constraints as the primary reason that they use the Internet to buy groceries.

\section{Visualization in Online Shopping}

In general, customers want more from their shopping experience than simply the selection of items from a long, scrolling, text-based list of items. Naturally, it is true that customers want to be able to access the facts about the items they are buying. The nutritional information of a specific breakfast cereal is an example. However, further to simply reviewing the facts about an item, the customer also wants to be able to visualize the item, to assess its shape or colour and to inspect the design features of the item. This 
applies to everything from buying digital cameras to the latest designer clothes.

The recent trend in online shopping is taking the visualization of items online one step further than fundamental snapshots of the items. Three dimensional models of items are widely used within online shopping by major companies such as Sony, Tesco, Amazon, EBuyer, Panasonic, 3Com, Lexmark and Dell. These companies are dealing with one of the main challenges of online shopping, namely the ability of the customers to have some experience of the items before they purchase them.

The use of $3 \mathrm{D}$ models enables these companies to represent and convey their products more fully [7] to the customer. The main use of 3D models is to show every angle of a product. Some companies also integrate animation and interaction. Furthermore, some companies provide models for the customer so that he/she can virtually "try on" the item. In particular, this concept applies to fashion sales but also to areas such as hair dressing, where the customer can visualize, beforehand, what a hairstyle/colour would look like on them. These technologies are increasingly popular and when used they result in improved sales [8].

\section{The "Easy Grocery" system}

Easy Grocery is an e-grocery ordering system that can be used by customers to do their grocery shopping online.

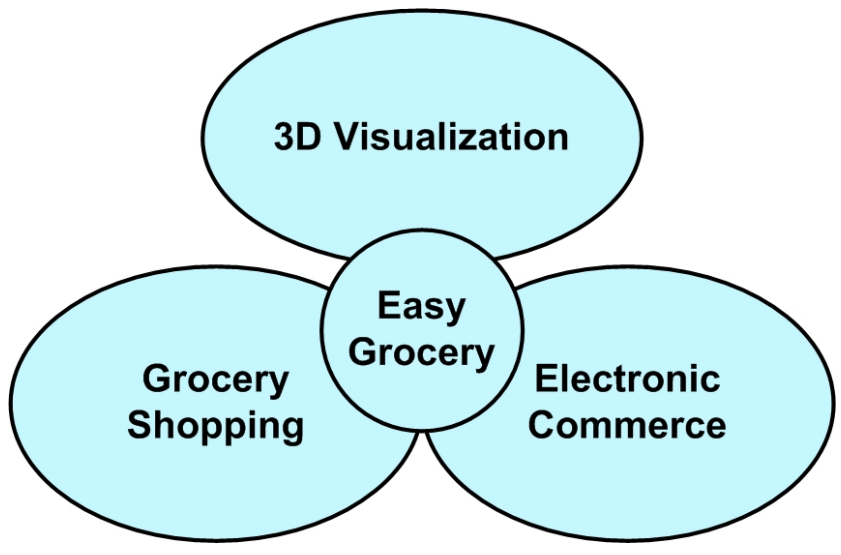

Figure 1: The Easy Grocery domain

The subject domain of Easy Grocery is shown in Figure 1. Fundamentally, Easy Grocery uses techniques from 3D visualization in order to enhance the customer's experience of e-grocery. Thus, the main aim of Easy Grocery is to provide consumers with a familiar shopping environment.

Some of the common complaints about e-grocery systems include

- $\quad$ orientation problems: consumers not being able to find the correct items

- precision issues: consumer uncertainty in their product selection, and,
- the unfamiliar experience of e-grocery shopping for first time users

Easy Grocery uses a 3D world that provides a platform from which these issues can be addressed.

Therefore, the key issue is the system interface to the consumer. It is understood [9] that an effective interface design is one that follows the user's 'mental model' of the scene (and not that of the developer). Based on their own experience of shopping in their local supermarket, consumers have a lot of knowledge of the location of everyday items of food within their local supermarket. This is the main advantage of Easy Grocery which capitalizes on the specialist knowledge of the user.

\subsection{Navigation within the Store}

The Easy Grocery store is portrayed in 3D at all times. This provides a complete, all angle interrogation of any item of merchandise anytime. As the user moves through the store, the items within the current view are transformed.

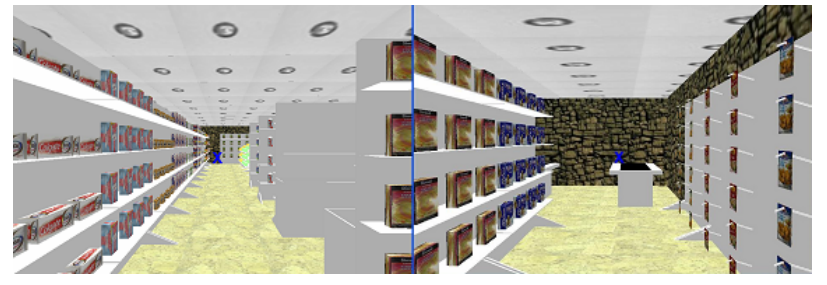

Figure 2: 90 Degree view transformation

The traditional cursor keys are employed to move the view (user) around the store. The mouse is also used to rotate the view (akin to the user moving their head). Figure 2 shows a view transformation from one corner of the store. The view is rotated around the $\mathrm{Y}$ axis so as to look down another aisle. This transformation is completed upon the user moving the mouse left or right. In order to keep the system close to reality the upside down backward viewing is restricted. Additionally, actions such as walking through shelves, stacks, and walls are restricted. Store navigation and view transformations are completed at the request of the user.

\subsection{Using Easy Grocery}

When using Easy Grocery the consumer places the cross in the center of the screen over the product they wish to purchase. The left mouse button can then be used to place the selected product in the consumer's trolley.

Alternatively, right clicking on a selected product allows the user to view details of the product. Easy Grocery provides the detail of any product when requested by the user [10]. These details are not visible to the user unless requested, thus allowing for a swifter, more efficient shop for those who are more experienced. All information 
can be displayed about each product that exists within the store. Figure 3 shows the details of a pizza within Easy Grocery. In this figure the exact weight and dimensions can be seen, amongst other items of data. The current details dialog is simple but functional.

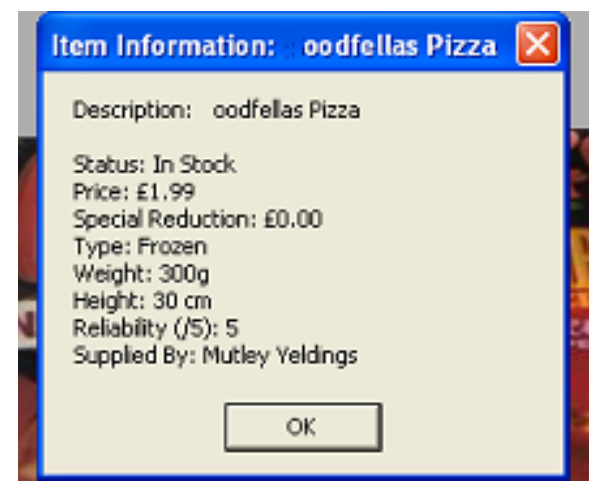

\section{Figure 3: Product details when requested}

Whilst shopping, tracking your orders is supported by the Easy Grocery built-in Order Manager. A snapshot of the Order Manager is shown in Figure 4. In this snapshot, three orders are shown, one of which is due to be delivered on the $21^{\text {st }}$ September 2006. The customer has selected these delivery dates. The cost of each order is shown as well as the current status of the order. Orders can have one of four states. These include: Just ordered, Picking, Delivered and Refunded.

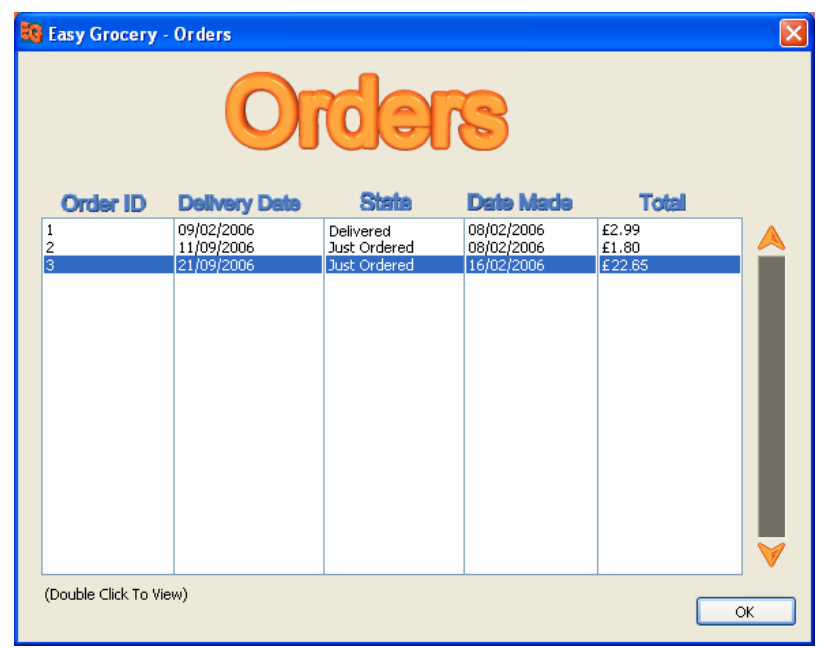

Figure 4: Order summary screen

From the Order Manager it is possible to view the details of any order by double clicking upon that order. This will provide the user with all of the order details shown in the Products Ordered window. A snapshot of the Products Ordered window, for Order Number Three, is shown in Figure 5. In this snapshot, the items that constitute Order Three are shown in detail, including the quantity of each item required and their unit prices.

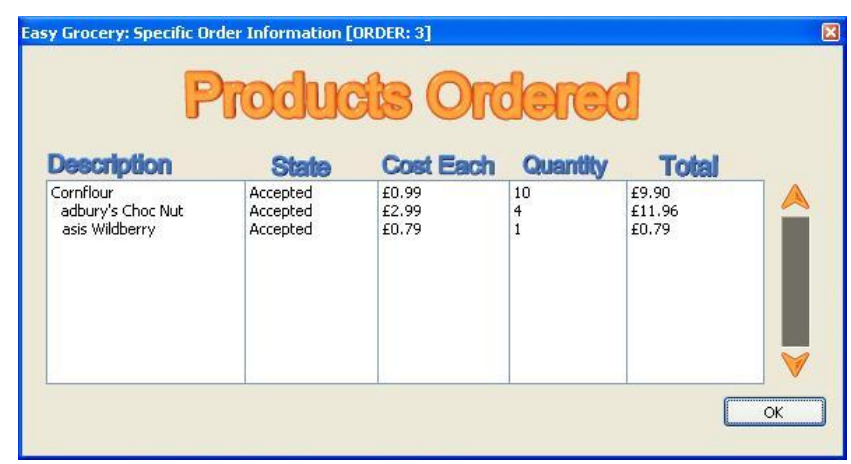

Figure 5: Specific order details

Finally, based on the fact that customers often order very similar goods repeatedly, Easy Grocery provides the user with the facility to view orders which they made in the past. All orders made within the past 24 months can be viewed by the user at any time. This can be very useful as it helps users "remember" a special wine they once ordered for a certain visitor or for other speciality and seasonal shopping. Specific items within an order can have one of three states. These are: Accepted, Refunded and Waiting for stock.

\subsection{The use of 3D visualization}

In contrast to traditional e-grocery systems, shopping within a 3D online supermarket provides additional information about the merchandise.

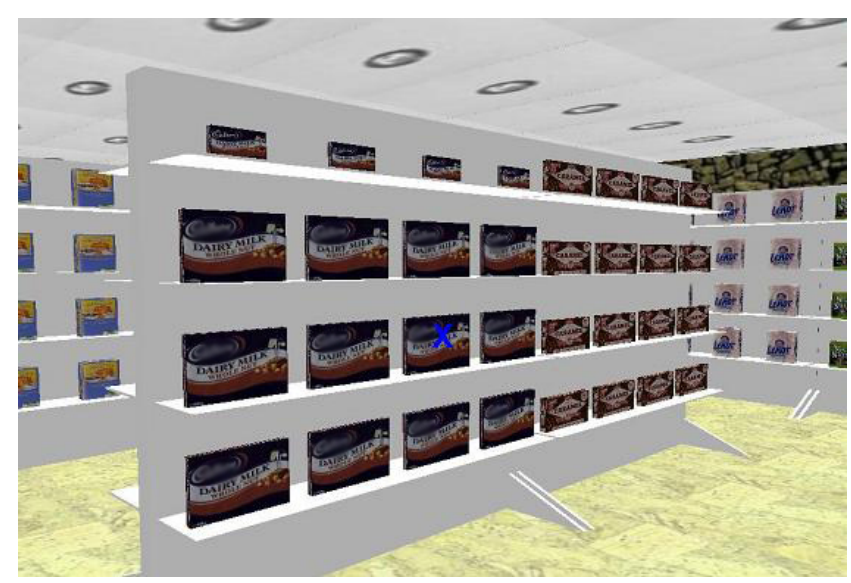

Figure 6: Natural magnitude ruling

Figure 6 shows a snapshot from the Easy Grocery system. In this snapshot, four shelves of chocolate bars are shown (for demonstration purposes). From the snapshot, it is clear that the chocolate bars on the top shelf are significantly smaller than the others. As a result of the visualization of the chocolate bars, this information is 
obvious. However, this is exactly the type of information that traditional text-based, HTML e-grocery systems fail to convey. Clearly, receiving (and paying for) the correct quantity of groceries is a major part of customer satisfaction.

\subsection{Store Layout}

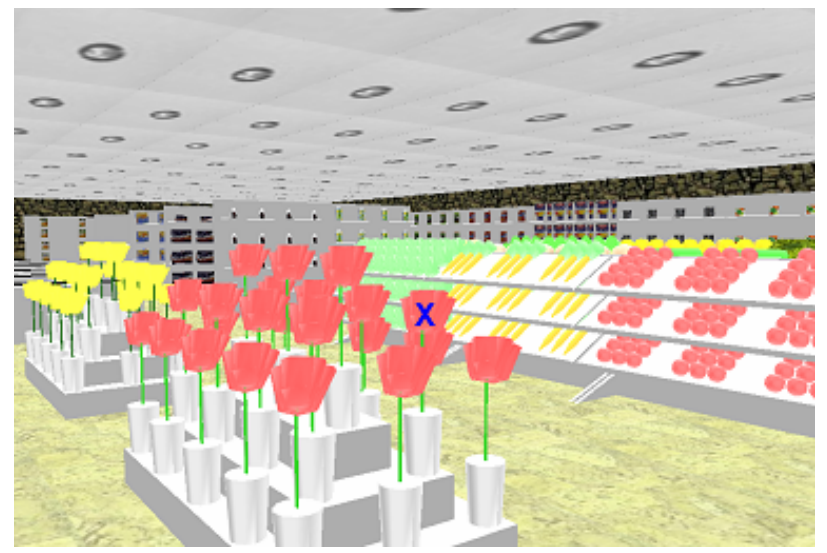

Figure 7: Spatial encoding, areas of the store

Most supermarkets have complex stock placement systems based on many factors. The concept of gathering similar types of product together within the store results in the creation of specialized areas of the store. For example, most supermarkets have a freezer section and a fresh produce section. This spatial encoding can be mimicked by Easy Grocery.

The snapshot of Easy Grocery, shown in Figure 7, depicts how these areas can be perceived from the far end of a store. Thus, the type of product is given by the product's location within the store. Other attributes of products can also be represented by their location, such as special offers, which are located at strategic points.

\subsection{Online shopping locally, anywhere}

Easy Grocery can dynamically rearrange every aspect of the online store to match the consumer's own personal preferences. Thus, the consumer can decide how the store will be laid out. Furthermore, Easy Grocery can be rearranged to exactly match the layout of the consumer's local supermarket. Therefore, if the user is familiar with a particular supermarket, Easy Grocery can transform itself to match the layout of this supermarket. Every item of merchandise is relocated to match that request. The dimensions of the supermarket are emulated, walls are resized, stacks are relocated, shelves are rearranged, and products are restocked. Consequently the user is then able to apply their expert knowledge of this familiar environment to their online grocery shopping experience.

This has many benefits for consumers. For example, a consumer living in Edinburgh could browse and shop within a store they know well in London without having to go there. The geographically local store would then deliver the goods as usual, even though the consumer may have experienced the layout of another store.

\subsection{The Easy Grocery Structure}

The system structure of Easy Grocery involves two major divisions: the server and the client. The client is a light weight 3D environment with accompanying system management. The small client handles both the 3D environment and the system control. System control includes functionality such as Internet communications, order management, store settings and launching the 3D environment.

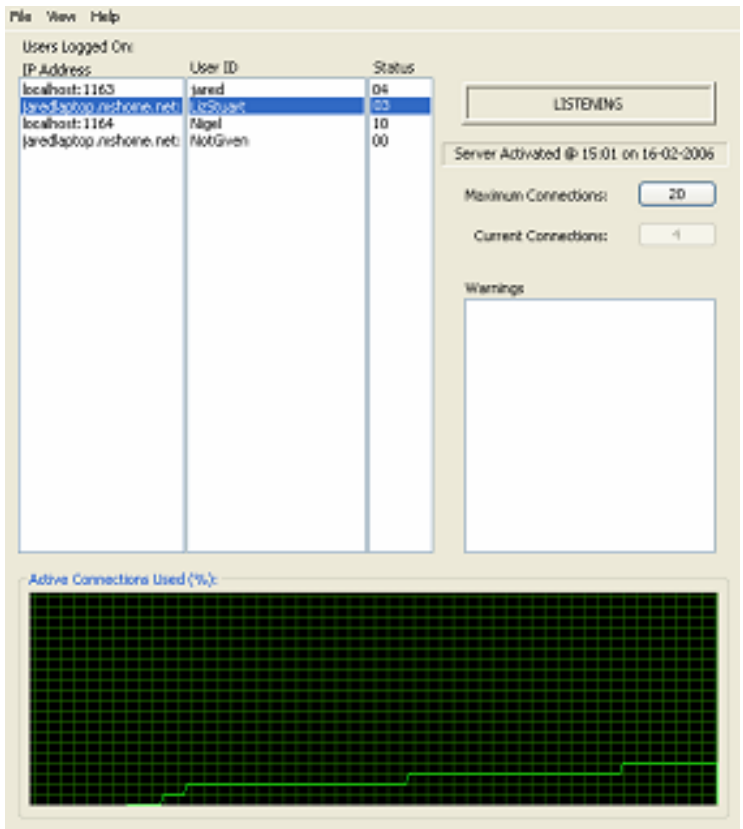

Figure 8: The server's connection control

The server side of the system includes database control, Internet communications and load management. A snapshot of the local shop server is shown in Figure 8. All current consumers are visible on the server's list of users. This allows Easy Grocery to handle large amounts of users and to easily detect when the quantity of users is approaching the system's limit. The connection monitor also records the connection total over time. This enables the system manager to gain vital information about connection habits.

This server - client system enables the content, such as order data, to be the only information that is sent across the Internet. Data transfer within standard HTML, form-based, grocery systems requires the complete form to be downloaded as well as the "order data", in order to send the data inputted by the user. As the form is the larger part 
of the communication, this results in a slow and ineffective transmission of the data required.

Easy Grocery supercedes this style of system by solely sending the content data. It only requires the content to be downloaded, not any of the data to do with the presentation and visualization system. All of this communication between the client and the server is encoded in a light weight protocol.

The system model is thus made flexible enough to split customer orders between several suppliers. Therefore, the Easy Grocery system can allow a number of local producers or retailers to act as one online supermarket thereby creating online distribution for smaller, local producers.

\subsection{HTML Compatibility}

The Easy Grocery system works in parallel with the current traditional HTML e-grocery systems. Thus, a consumer may choose to use the traditional HTML view for their shopping or to utilize the Easy Grocery system. The purchasing system will produce the same result regardless of the view chosen by the user. Hence, the supermarket is supplied with the same information in each case.

\section{Conclusions}

Easy Grocery can provide significant advantages for consumers who are both new and experienced to online grocery shopping. The main advantage is the familiarity and confidence that shopping in a familiar environment provides. The knowledge of product placement results in a much faster and satisfactory shopping experience. Since groceries are classified as "high touch" items, Easy Grocery engages the consumer by providing them with the virtual experience of seeing and possibly inspecting the product.

Easy Grocery has the potential to deliver four main improvements to the current e-grocery shopping experience

- An increasing to the popularity of e-grocery shopping due to the use of a familiar environment for the user.

- Accuracy of ordering due to the fact that users can visually inspect and view the physical attributes of the items they are ordering.

- Faster shopping experiences due to reduced search times.

- The potential for future expansion and sales enhancing features.

Empirical testing showed that the navigation and control system is a new experience for many people. However, the average shopping times for randomly generated shopping lists were decreased when compared to current World
Wide Web technologies. All of those who assessed Easy Grocery, elected Easy Grocery over the traditional egrocery alternatives.

\section{Future Work}

Consumers who shop in traditional bricks-and-mortar settings also do so for the social interaction that the environment can provide. One facet of future work is the development of a communal shopping environment where a consumer can make their presence known and interact with fellow shoppers.

Additionally, bricks-and-mortar shopping environments have a lot of advantages in terms of friendly assistants and celebrity sponsors. Future work could also include celebrity employees, such as chefs like Jamie Oliver, and personal health advisors. In a world where consumers are becoming increasingly mindful of what they eat, to have a professional, such as the food guru Gillian Mc Keith, providing you with accurate nutritional advice and recommendations on products would have an impact on both sales and health.

A consumer's ability to find new products they require is greatly enhanced by shopping within their own local store. However, there are still likely to be products that a consumer cannot find, particularly if it is a new product to the consumer or the store. A search feature will be implemented where the customer can be 'whisked' from their current position in the store straight to the product required.

Although Easy Grocery was conceptualized to remedy traditional e-grocery deficiencies, the world of e-grocery has expanded well beyond its origins. As such e-grocery has many beneficial and constructive techniques that can be propagated to Easy Grocery. Techniques include, but are not limited to, the consumer starting a shop with the items from the consumer's last purchase already in their trolley and recipe based shopping.

On an abstract level Easy Grocery may be disseminated into other domains. Such scenarios could involve an operator searching for hundreds of items amongst thousands. The items would be grouped and ordered spatially based on the required factors. This idea can be implemented to successfully select specific data from a large number of alternatives.

There is significant opportunity for future expansion of this concept. Current e-grocery systems are generally flawed by the fact that they are designed based on the software engineer's implementation model of the process of shopping. For example, the picture and text layout of current e-grocery systems conform to a developer friendly model.

However, the user has their own cognitive model of the shopping process, such as the layout of their preferred supermarket, due to repetitive and regular shopping. This knowledge needs to be exploited more substantially. It is 
anticipated that such an implementation of a user-based model of the shopping process would revolutionize online shopping

\section{References}

[1] A. Seth. \& G. Randall. 1999. The Grocers: The Rise and Rise of the Supermarket Chains. Kogan Page.

[2] R. Cailliau, J. Gillies, R. Cailliau. 2000. How the Web was Born, The Story of the World Wide Web, Oxford University Press.

[3] K. Partch, 2001. The Trouble with Online Grocery, Supermarket Business Magazine, volume 56, issue 8.

[4] M. Kempiak and M. A. Fox, 2002. Online Grocery Shopping: Consumer Motives, Concerns, and Business Models, First Monday, volume 7, number 9.

[5] J. Heikkila, J. Kallio, T. Saarinen and K. Virpi, 1998. Grocery Shopping for the Elderly and Disabled: Finnish EC Experiments, Electronic Markets, volume 8, number 2.

[6] B. Cude and M. Morganosky, 2000. Online Grocery Shopping: An Analysis of Current Opportunities and Future Potential, Consumer Interests Annual, volume 46.

[7] Kaon Interactive Inc, [onlne] http://www.kaon.com/ demos.html.

[8] L. Gill, Future of 3D E-Commerce (The), eCommerce Times [Online], 2002. http:// www.ecommercetimes.com /story/19868.html

[9] A. Cooper, About Face: The Essentials of User Interface Design, IDG Books, 1995.

[10] Shneiderman, B., The eyes have it: A task by data type taxonomy of information visualizations, Proc. IEEE Symposium on Visual Languages '96, IEEE, Los Alamitos, CA (September 1996), 336-343 